\title{
Feminismo De(s)colonial como Feminismo Subalterno Latino-Americano
}

\author{
Luciana Ballestrin' (iD) 0000-0001-6787-8406 \\ 'Universidade Federal de Pelotas, Instituto de Filosofia, Sociologia e Política (IFISP), \\ Pelotas, RS, Brasil, 96010-770-ifisp@ufpel.edu.br
}

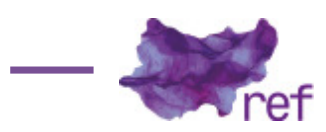

\begin{abstract}
Resumo: No presente artigo argumento que o feminismo de(s)colonial pode ser entendido como um feminismo subalterno, inclusive na trajetória dos feminismos latino-americanos. Ao mobilizar um discurso crítico à modernidade e à colonialidade, inclusive dentro do próprio movimento feminista, o feminismo de(s)colonial se insere em uma história mais ampla do feminismo terceiro-mundista que antecipou aquilo que chamo de paradoxo da representação feminista. Sugiro que o debate feminista de(s)colonial seja compreendido em sua complexidade teórica e prática, argumentando que sua novidade e distinção reside na construção e na articulação da ideia de descolonização como utopia política de diferentes feminismos subalternos latino-americanos nas duas últimas décadas.
\end{abstract}

Palavras-chave: Feminismos subalternos; feminismos latino-americanos; feminismo de(s)colonial; giro decolonial.

\section{Decolonial Feminism as Latin American Subaltern Feminism}

Abstract: In this article I propose the understanding of decolonial feminism as Latin-American and subaltern feminism. In the last two decades, decolonial feminism has developed a critical discourse on modernity and coloniality outside and inside of Latin-American feminism. As well as Third-World feminism, decolonial feminism presents the paradox of feminist representation. There is a necessary articulation between the theory and practice in decolonial feminist project and its main novelty is to reconstruct the decolonization as a political utopia, along w others Latin-American and subaltern feminisms.

Keywords: Subaltern Feminisms; Latin-American Feminisms; Decolonial Feminism; Decolonial Turn.

\section{El Feminismo De(s)colonial como Feminismo Subalterno Latinoamericano}

Resumen: En el presente artículo sostengo que el feminismo de(s)colonial puede entenderse como un feminismo subalterno, incluso en la trayectoria de los feminismos latinoamericanos. Debido a la formulación de un discurso crítico cerca de la modernidad e la colonialidad en el propio feminismo, el feminismo de(s)colonial es parte del larga historia del feminismo tercero mundista que anticipado el paradoja de la representación feminista. Sugiero que el debate feminista de(s)colonial se entienda en su complejidad teórica y práctica, argumentando que su novedad y distinción radica en la construcción y articulación de la idea de descolonización como una utopía política de diferentes feminismos subalternos latinoamericanos en las últimas dos décadas.

Palabras clave: Feminismos subalternos; feminismos latinoamericanos; feminismo de(s)colonial; giro decolonial.

\section{Introdução}

Atualmente, o feminismo é o movimento global mais importante em termos de inovação teórica, intervenção social, atuação política e resistência democrática. Essa afirmação pode ser facilmente verificada nos mais distintos espaços, em longínquas partes do mundo. De fato, a globalização do movimento feminista acentuou as fissuras nas relações de poder que perpetuam desigualdades e hierarquias de gênero em uma escala internacional. Prova disso é a reação 
também global às suas conquistas, articuladas em discursos antifeministas e misóginos explícitos que participam da reabilitação de uma extrema-direita violenta e autoritária.

No Brasil, país fundamental para entender essa transformação ideológica agressiva e materializada no impeachment da ex-presidenta Dilma Rousseff e no feminicídio político da vereadora Marielle Franco, o índice de violência contra as mulheres aumentou de uma forma geral. Eleitas por partidos políticos de esquerda, a violência política de gênero sofrida por essas duas mulheres é muito representativa do afastamento e da morte da própria democracia brasileira. Não por acaso, a questão de gênero está no epicentro da crise contemporânea das democracias liberais, ${ }^{1}$ sendo a expressão "ideologia de gênero" utilizada por setores neoconservadores em uma espécie de ofensiva global e atualizada da "caça às bruxas" (Flávia BIROLI, 2018; Silvia FEDERICl, 2017).

O desenvolvimento do movimento feminista ao longo do século XX com frequência é pensado em termos de "ondas" que sintetizam suas conquistas em termos de direitos civis, políticos e sociais. Geralmente tomadas a partir de um referencial da história do movimento de mulheres em países específicos do Ocidente, a periodização dessas fases não necessariamente reflete uma sincronia geográfica do movimento feminista. O feminismo de(s)colonial, corrente analisada neste texto, questiona

en sintonía con el proyecto que devela la colonialidad como lado oscuro de la modernidad, [...] de forma radical la lectura de una historia ascendente de 'conquista de derechos para las mujeres' que se estima ha comenzado en Europa y los Estados Unidos y luego se ha ido extendiendo al resto del mundo, producto de la aparición del feminismo como movimiento universal, un "fenómeno progresivo, que se produciría a medida que la llustración fuera desarrollando y explicitando sus propios presupuestos (Amorós s.f.) (Yuderkys MIÑOSO, 2014, p. 32).

Essa observação importa para aquelas estudiosas interessadas em tornar o global cada vez mais representativo de outros contextos regionais, nacionais e locais, dada a diversificação das histórias e trajetórias das lutas feministas. A preocupação em tornar o feminismo mais representativo - e, portanto, inclusivo - em termos de identidades tem sido uma questão fundamental para sua agenda contemporânea, assumindo internamente um caráter conflitivo, estratégico e político pelo menos desde os anos 1980.

Naquela conjuntura, várias transformações importantes ocorreram nas ordens nacional e internacional. A divisão entre Primeiro e Terceiro Mundo foi substituída pela divisão Norte e Sul Global; o neoliberalismo começava a ser testado pela primeira vez nos países centrais (Inglaterra e Estados Unidos); a globalização estimulava o estabelecimento da multipolaridade; o multiculturalismo afirmava a importância da política das identidades afirmativas; as sociedades civis foram reabilitadas nos âmbitos domésticos redemocratizados. Na década seguinte, o debate sobre a democratização do sistema internacional fortaleceu a controversa e disputada ideia de uma sociedade civil global, agente fundamental para o alargamento de diversas agendas internacionais em torno dos direitos humanos e meio-ambiente no âmbito das Nações Unidas (ONU). Algumas dessas mudanças contribuíram direta e indiretamente para a internacionalização do movimento feminista, sendo essa dinâmica estimulada pela ONU desde os anos 1970.

Seu engajamento na promoção dos direitos das mulheres institucionalizou várias iniciativas, tais como a definição do Ano Internacional das Mulheres e a ocorrência da primeira Conferência Mundial das Mulheres na cidade do México (1975); o estabelecimento da Década da Mulher (19761985); a elaboração da Convenção sobre a Eliminação de Todas as Formas de Discriminação contra a Mulher (1979); a realização da segunda Conferência Mundial das Mulheres em Copenhague (1980), seguida da terceira em Nairóbi (1985) e da quarta em Pequim (1995); a incorporação das questões de gênero nos Objetivos do Milênio (2000); a adoção da Resolução 1325 pelo Conselho de Segurança (2000), que estipula a representação e participação das mulheres na prevenção, gestão e resolução de conflitos armados; a criação da ONU Mulheres em 2010.

Paralelamente a esse conjunto de ações, a transnacionalização e a "onguização" do movimento feminista foram dinâmicas incentivadas pelo seu processo de internacionalização (Sonia ALVAREZ, 1998). Assim, a construção discursiva do direito das mulheres como direitos humanos, a adoção da perspectiva de gênero em vários órgãos e programas do sistema ONU, sua articulação com a agenda do desenvolvimento através da noção de empowerment, o tratamento da questão da violência contra a mulher e o incentivo à representação política feminina nos contextos nacionais foram resultados de um longo percurso interativo entre essa organização intergovernamental e centenas de organizações não governamentais. É fundamental observar que essa construção não se deu necessariamente de forma consensual, sendo sua desejabilidade questionada por diversas expressões críticas do movimento feminista ao redor do mundo. Muitas delas interpretam internacionalização como "colonização", principalmente devido aos processos maiores que a estimulam - globalização e neoliberalismo.

\footnotetext{
${ }^{1}$ Devo esse raciocínio específico à colega e pesquisadora Flávia Biroli (UnB).
} 
Assim, a participação onusiana na globalização/internacionalização/transnacionalização do movimento feminista tem sido uma questão bastante conflituosa, disputada e controversa em seu interior. Alguns dos principais argumentos giram em torno da questão da perda de autonomia e independência das organizações feministas e de mulheres; da versão (neo)liberal do feminismo difundida pela organização; da despolitização e domesticação da categoria "gênero" pelo uso excessivamente tecnocrático, assim como pelo seu próprio entendimento ocidental; do favorecimento das organizações feministas mais profissionalizadas e burocratizadas (ALVAREZ et al., 2003; MIÑOSO, 2014).

Do neoliberalismo ao colonialismo, as críticas feministas das subalternidades globais também atravessaram o próprio movimento feminista. A discussão em torno da "mulher do Terceiro Mundo" - categoria que conecta feminismo, pós-colonialismo e marxismo - exemplificou a incorporação de uma dimensão geopolítica pela teoria e pela prática feminista, criando um antagonismo entre o feminismo hegemônico e suas variações subalternas. A (geo)politização do debate feminista evidenciou diferenças irreconciliáveis na construção de sua cosmopolitização, expondo dimensões conflitivas irreconciliáveis dentro do próprio movimento global de mulheres.

É precisamente nessa dimensão que reside um importante paradoxo da representação dos feminismos contemporâneos: sua crescente fragmentação e diversificação é capaz de gerar (łambém) certo exclusivismo na inclusividade e particularismo no pluralismo que comportam a dilatação de suas identidades. Tal entendimento, que envolve ordens teórica e política, encontra manifestações empíricas no movimento feminista latino-americano pelo menos desde os anos 1980 (ALVAREZ et al., 2003). Os feminismos subalternos em geral e o feminismo de(s)colonial ${ }^{2}$ em particular têm desempenhado um papel que auxilia na exposição dessas contradições, expressando tal paradoxo da representação feminista. ${ }^{3}$

Para contribuir com o debate sobre os feminismos subalternos, o presente artigo se debruça mais especificamente sobre o feminismo de(s)colonial. Sua importância para a análise feminista poderia ser justificada por vários motivos, ressaltando aqui o caráter da novidade e da criatividade que suas teorizações e práticas trazem para o debate feminista regional e global. Neste sentido, destaco a articulação e a construção da descolonização como utopia política feminista e subalterna na América Latina, aproximadamente nas duas últimas décadas. Neste texto, sugiro que isso caracteriza distintivamente o feminismo de(s)colonial, sendo ele próprio um feminismo subalterno que articula diferentes expressões feministas - também subalternas - com propósitos descolonizadores.

O feminismo de(s)colonial tem proposto reflexões e intervenções de uma forma bastante inovadora, não podendo ser reduzido a um feminismo exclusivamente acadêmico ou militante. Há, antes, imbricamentos, trânsito e sobreposição de diversos papéis das autoras e interlocutoras que organizam publicações, encontros e espaços de confluência relacionados a esse debate. Muitas delas são professoras, pesquisadoras e/ou ativistas de longa data do expressivo campo feminista latino-americano.

Este artigo está dividido em três seções em que se buscou caracterizar e relacionar os feminismos subalternos, latino-americano e de(s)colonial. Na primeira, objetivou-se compreender o feminismo de(s)colonial como um feminismo subalterno, inserindo-o em uma trajetória mais ampla do feminismo terceiro-mundista que antecipa aquilo que chamei de paradoxo da representação feminista. Posteriormente, foram trazidas algumas observações sobre a conformação do feminismo latino-americano, de modo a conhecer o desenho de sua versão hegemônica de acordo com a literatura. Na última seção, sugeriu-se que o debate feminista de(s)colonial seja compreendido em sua complexidade teórica e prática, argumentando que sua novidade reside na (re)invenção e na (re)articulação da ideia de descolonização como utopia política de diferentes feminismos subalternos latino-americanos.

\section{Feminismo de(s)colonial como feminismo subalterno}

O feminismo de(s)colonial, enunciado como tal, remonta à primeira década do século XXI. Em relação ao feminismo, há influências teóricas do feminismo pós-colonial e terceiro-mundista; já em relação ao pós-colonialismo, suas influências teóricas derivam - muitas vezes explicitamente - da inflexão decolonial latino-americana. Como desdobramento e ampliação do giro decolonial, mas também como confluência dos feminismos latino-americanos diversos, é preciso destacar que o feminismo de(s)colonial tem na referência de "Abya Yala" seu principal lugar de enunciação e reflexão. "Abya Yala" significa "Terra madura", "Terra Viva" ou "Terra em florescimento" na língua

\footnotetext{
${ }^{2} \mathrm{Na}$ terceira e última seções justifico o uso no singular e a estratégia do emprego de parêntesis para a terminologia "feminismo de(s)colonial".

${ }^{3}$ Não é meu objetivo aqui desenvolver teoricamente essa ideia da forma como ela mereceria ser desenvolvida. Compartilha-se para o debate, contudo, essa proposta que parece ser promissora para trabalhar as contradições $e$ os paradoxos dos feminismos contemporâneos, especialmente no tocante às questões sobre identidade, representação, inclusão e democracia.
} 
do povo Kuna, originário do norte da Colômbia e que vive atualmente na costa caribenha do Panamá. É importante destacar que a expressão tem sido utilizada como contraponto à noção de "América", tendo sido utilizada pela primeira vez em 2004 na Il Cumbre Continental de los Pueblos y Nacionalidades Indígenas de Abya Yala realizada em Quito. A utilização dessa referência, portanto, faz "parte de um processo de construção político-identitário em que as práticas discursivas cumprem um papel relevante de descolonização do pensamento e que tem caracterizado o novo ciclo do movimento indígena, cada vez mais movimento dos povos originários" (Carlos Walter PORTO-GONÇALVES, 2006).

De certa maneira, essa construção atualiza o feminismo pós-colonial e terceiro-mundista, reforçando a importância geográfica e histórica como construtora de identidades feministas subalternas. A substituição do termo Terceiro Mundo pelo de Sul Global na ordem internacional é captada em porções do feminismo de(s)colonial em suas alusões ao "sul", ainda que haja variação nas menções acerca de pertencimentos geoculturais.

Construindo-se como um feminismo crítico, radical e autônomo, o feminismo de(s)colonial absorve dos feminismos latino-americanos diferentes vertentes, propostas e debates travados ao longo de sua larga trajetória das últimas quatro décadas. É fonte de inspiração a heterogeneidade das mulheres no continente transamericano como um todo, inseridas em situações e relações de subalternidades diversas e comumente sobrepostas referentes à classe, raça, etnia, cultura, orientação sexual, nacionalidade, geografia. Pode-se então afirmar que o feminismo de(s)colonial participa e deriva tanto da história do feminismo pós-colonial quanto do feminismo latino-americano em sua diversidade, apresentando-se como uma espécie de síntese em termos simbólicos.

Ambas expressões do feminismo podem ser associadas ao feminismo terceiro-mundista. $O$ encontro ocorrido entre feminismo e pós-colonialismo nos anos 1980 construiu um antagonismo entre o feminismo ocidental e os feminismos não ocidentais. A expressão "feminismos subalternos", presente nos próprios discursos feministas, caracteriza um jogo relacional e discursivo em torno de tensões e disputas internas ao movimento feminista e de mulheres, relacionadas às questões de identidade, representação e poder (Luciana BALLESTRIN, 2017a).

Os feminismos subalternos podem ser entendidos como aqueles movimentos de mulheres que identificam na existência de um feminismo hegemônico a promoção de uma outra relação de subalternidade sobre mulheres historicamente subalternizadas. Partindo desse entendimento, constroem de maneira discursiva e relacional uma positividade em torno da noção de subalternidade, ao gerar uma identidade provisoriamente essencialista, estratégica e antagônica à sua versão hegemônica. Contrariando assim a própria vocação pós-colonial da crítica aos binarismos opostos, os feminismos subalternos apostam em sua diferenciação radical do feminismo hegemônico, encarando-o no limite da inimizade (BALLESTRIN, 2017a).

A expressão "feminismos subalternos" alude, assim, à subalternidade no interior do próprio feminismo, nos termos de Spivak (Stephen MORTON, 2004). É importante observar essa dupla construção: ao mesmo tempo em que denunciam o silenciamento de várias expressões do feminismo, os feminismos subalternos agenciam um antagonismo irreconciliável diante um feminismo hegemônico do Primeiro Mundo ou Norte Global: elitista, ocidental, branco, universalista e etnocêntrico. Isso revela um essencialismo estratégico e binário no interior do próprio feminismo, e, portanto, nas relações intragênero. É importante notar que este antagonismo vai sendo acentuado a partir da identificação e interiorização de outros marcadores que ampliam o leque das interseccionalidades - ao lado e a partir de suas categorias centrais (classe, raça, etnia, orientação sexual, identidade de gênero) (BALLESTRIN, 2017a).

O feminismo hegemônico, dessa forma, passou a ser exposto em seu universalismo, etnocentrismo, anglo-eurocentrismo, (neo)liberalismo, branqueamento e negligência de questões coloniais e raciais que atravessam etnias, nacionalidades e geografias. Também, passou a ser retratado como um feminismo do Primeiro Mundo ou Norte Global, muito pouco sensível às questões das "outras" mulheres do feminismo. Nesta disputa discursiva, simplificações, generalizações e não diferenciações em termos de identidade, representação e interesse acabaram por surgir. Estabeleceu-se uma polaridade antagônica e irreconciliável no interior do feminismo, em torno de uma diferença aparentemente geocultural e geopolítica. O feminismo terceiro-mundista, ao denunciar o colonialismo intelectual das acadêmicas feministas ocidentais, construiu uma cadeia de equivalência discursiva inversa. Desse modo, envolveu-se em uma espécie de duplo jogo discursivo: assim como o feminismo ocidental passou a ser julgado por essencializar, inferiorizar e vitimizar as mulheres do Terceiro Mundo, o feminismo terceiro-mundista respondeu utilizando a mesma operação ao essencializar, superiorizar e responsabilizar as mulheres feministas do Primeiro Mundo (BALLESTRIN, 2017a).

A expressão "feminismos subalternos" é capaz de abarcar uma pluralidade constitutiva dos feminismos contemporâneos, auxiliando na compreensão do paradoxo da representação feminista. ${ }^{4}$ Por meio dela, é possível incluir movimentos amplos e específicos de mulheres e feministas

\footnotetext{
${ }^{4}$ Por isso a preferência em abordar "feminismos subalternos" no plural e "feminismo hegemônico" no singular.
} 
(acadêmicas, ativistas, autônomas, partidárias), tais como o feminismo pós-colonial, terceiromundista, transcultural, fronteiriço, latino-americano, "do sul", "de cor", negro, indígena, comunitário, lésbico, islâmico. Em geral, este amplo espectro de caracterizações está relacionado com marcações geopolíticas, étnico-raciais e culturais (BALLESTRIN, 2017a).

Os feminismos subalternos possuem algumas representações, estereótipos e construções mencionadas pela literatura feminista pós-colonial, latino-americana e decolonial, em antagonismo ao feminismo hegemônico. O marcador geopolítico dos feminismos subalternos em geral diz respeito às regiões da América Latina, Caribe, Ásia, Oceania ${ }^{5}$ e África, as quais projetam noções dos mundos "não ocidental", "Terceiro Mundo" e do "Sul Global". Em contraposição, o feminismo hegemônico está associado ao "Ocidente", ao "Primeiro Mundo" e ao "Norte Global", espelhando as reivindicações dos movimentos feminista e de mulheres dos países europeus, Estados Unidos e Canadá. Enquanto o feminismo hegemônico possui uma projeção mais universal e global, os feminismos subalternos são vistos como particulares e locais, podendo ser influenciados pelas dinâmicas de migração ${ }^{6}$ e diáspora. Seus marcadores espaço-temporais e político-culturais se desdobram nos âmbitos comunitários, comunais, rurais, não modernos e religiosos (por ex., feminismo islâmico). De sua parte, as concepções hegemônicas do feminismo estão relacionadas ao moderno, secular, nacional e urbano.

No que se refere aos marcadores raça, etnia, cor, identidade de gênero e orientação sexual, as representações hegemônicas do feminismo contemplam geralmente as brancas, cisgênero e heterossexuais; suas representações subalternas se referem às mulheres negras, mestiças, ${ }^{7}$ indígenas e "chicanas", sejam elas transgênero, não binária, homossexual e bissexual. ${ }^{8}$

Em termos de classe, as representações hegemônicas abarcam as mulheres das classes médias e altas, sendo as mulheres pobres sua representação subalterna antagônica. Enquanto essas são tidas como pouco ou não escolarizadas, as mulheres escolarizadas e com formação acadêmica são as mais consideradas pelo feminismo hegemônico. Em decorrência, os postos de trabalho variam bastante, ainda que as posições marcadas pela situação de precariedade, vulnerabilidade e exploração mais acentuadas sejam ocupadas pelas mulheres representadas nos feminismos subalternos. Aqui, recorre-se novamente à crítica feminista terceiro-mundista que recusa a anulação da agência das mulheres sob as representações exclusivas de vitimização, violência e pobreza, enquanto o feminismo hegemônico encarna a libertação e emancipação das mulheres que podem desenvolver maior autonomia (BALLESTRIN, 2017a).

O feminismo de(s)colonial se constitui como um feminismo subalterno, inclusive, dentro da trajetória dos feminismos latino-americanos. Mais precisamente, ele aparece como articulador dos feminismos subalternos da região, por meio de um discurso crítico à modernidade e à colonialidade dentro do próprio movimento feminista. Este aspecto em particular remete à elaboração feminista pós-colonial ${ }^{9}$ e terceiro-mundista, responsável por inserir a categoria "colonialismo" para o interior do feminismo pela primeira vez na década de 1980. Antes de prosseguir com a exposição do núcleo argumentativo feminista de(s)colonial, faz-se importante contextualizar parte da trajetória do feminismo latino-americano, assim como o projeto do giro decolonial. O objetivo desta breve contextualização é reunir algumas condições empíricas e teóricas que estimularam direta ou indiretamente o surgimento do feminismo de(s)colonial.

\section{Feminismos latino-americanos}

Apesar de o primeiro congresso feminista regional datar de 1910, na cidade de Buenos Aires (Verónica SCHILD, 2017), a literatura especializada costuma retroceder aos anos 1970 para contar um pouco da história do feminismo no continente. Possuindo importantes particularidades no contexto daquilo que se convencionou chamar de segunda onda do feminismo, a organização das mulheres estava inserida em uma conjuntura pouco favorável por duas cenas relacionadas. A primeira dizia respeito à natureza de grande parte dos regimes políticos que vigoravam naquele período e a segunda às estratégias de resistência aos mesmos. Em outras palavras, os regimes autoritários, a clandestinidade das sociedades civis e os condicionamentos da esquerda revolucionária acabaram secundarizando a importância das reizvindicações feministas, em nome de lutas consideradas maiores ou prioritárias.

\footnotetext{
${ }^{5}$ Apesar do passado colonial, países como Austrália e Nova Zelândia usufruem de índices econômicos mais condizentes com o Norte Global, o que faz com que a Oceania transite entre as categorias Norte/Sul.

${ }^{6}$ As mulheres migrantes aparecem como sujeitas importantes para os feminismos que abarcam a América Central e do Norte.

${ }^{7}$ Nota-se que a denominação "mestiça" pode ser manipulada tanto nas representações dos feminismos subalternos quanto hegemônico, havendo menções na literatura da expressão unificada "mujeres blancas-mestiças".

${ }^{8} \mathrm{O}$ marcador relacionado à sexualidade foi incorporado após a revisão da literatura referente ao feminismo latinoamericano. A expressão lésbica do feminismo aparece desde os primeiros encontros feministas latino-americanos (SHILD, 2017).

${ }^{9}$ O feminismo pós-colonial se desenvolveu paralelamente à própria versão pós-estrutural do pós-colonialismo, tornandoo mais aberto e atento às questões relativas às mulheres e ao gênero.
} 
Na década seguinte, a reabertura política e o ressurgimento da sociedade civil foram fundamentais para a articulação e a construção de diferentes movimentos de mulheres e feministas na América Latina. Alguns dos registros mais importantes para se entender a formação desse associativismo continental se encontram na realização dos Encontros Feministas Latino-Americanos e Caribenhos, cuja primeira ocorrência se deu em 1981, na capital colombiana de Bogotá. As memórias e narrativas sobre esses Encontros, disponibilizadas pela literatura especializada, permitem conhecer não somente alguns dos principais debates e temas presentes naqueles espaços, mas também os principais conflitos e disputas internas do "campo feminista", entendido como um "campo(s) discursivo(s) de ação"10 (ALVAREZ, 1998; ALVAREZ et al., 2003; ALVAREZ, 2014).

A pesquisadora feminista Sonia Alvarez, referência central na área, descreve e analisa, juntamente com sete autoras, a importância desses encontros para o movimento feminista da região. Na prática, eles funcionaram como espaços críticos, transnacionais e transfronteiriços capazes de reconfigurar e renegociar discursos, práticas e identidades dos movimentos locais, nacionais e regionais (ALVAREZ et al., 2003). Diferentes "comunidades feministas latino-americanas" começaram a ser imaginadas, uma vez que esses encontros possibilitaram o engajamento e a conversa entre diferentes mulheres e grupos, muitas marginalizadas e subalternizadas nos seus países de origem, cujos feminismos emergiram de heranças (neo)coloniais semelhantes (ALVAREZ et al., 2003, p. 542-543). Construindo-se como espaços privilegiados para a observação de convergências e divergências da própria constituição do campo feminista latino-americano em suas diferentes expressões organizativas, temáticas, ideológicas, identitárias e geracionais, estes encontros foram representativos das disputas sobre os significados do próprio feminismo, muitas delas responsáveis pela marcação de diferenças profundas e antagônicas.

Segundo as autoras (ALVAREZ et al., 2003), a autonomia se constituiu em um importante princípio da identidade feminista na América Latina. Variando de acordo com o contexto dos anos 1980 e 1990, a preocupação com a independência do movimento recorreu frequentemente à necessidade de preservação da autonomia em relação a diferentes atores: organizações da esquerda revolucionária e partidos políticos em um primeiro momento; posteriormente, Estado, outros movimentos sociais, organizações não governamentais e agências de financiamento internacional. Ainda que o associativismo feminista latino-americano não seja objeto do presente texto, é interessante trazer um retrato do ano de 1990, onde 3.200 participantes se reuniram no Encontro realizado em San Bernardo (Argentina):

De fato, o Encontro de San Bernardo parecia sugerir que os feminismos latino-americanos e caribenhos haviam atingindo proporções massivas. A presença de mulheres de uma vasta arena do que hacer feminista, incluindo grupos independentes, sindicatos, ONGs, universidades, ministérios de mulheres recém-criados, e até parlamentares eleitas, sinalizaram que até 1990 a prática feminista tinha adquirido significativamente novas dimensões. A presença simultânea de mulheres de grupos 'autônomos', de centros de estudo e de arenas 'institucionalizadas' como partidos políticos e o Estado sugeria que os 'velhos' debates sobre autonomia haviam sido aparentemente superados (ALVAREZ et al., 2003, p. 549).

A década de 1990 foi palco de importantes transformações que impactaram nas formas de participação e representação da sociedade civil, oriundas do contexto democrático, neoliberal e globalizado à época em emergência. A ativação da sociedade civil global com o estímulo da ONU gerou novas estruturas de oportunidades para mobilização, por meio do impulso de transnacionalização e internacionalização das dinâmicas associativas. O feminismo latinoamericano foi bastante impactado por esse novo cenário, passando por um processo de "onguização" que reacendeu a antiga disputa por autonomia (ALVAREZ, 1998). O conflito foi traduzido como a disputa entre feministas "autônomas" e "institucionalizadas" (uma referência àquelas que trabalhavam em organizações governamentais e não governamentais), uma vez que cresciam as tendências relacionadas à formação de redes de advocacy, ao aparato (tecnocrático, burocrático e profissional) em torno das políticas públicas de gênero e aos preparativos das próprias conferências internacionais da ONU. No âmbito do Sétimo Encontro realizado em Cartagena (Chile), em 1996, o conflito atingiu um patamar traumático pelo grau do tensionamento interno entre determinados grupos. ${ }^{11}$

A dinâmica de expansão e transnacionalização do movimento foi também acompanhada pelas crescentes discussões envolvendo as "práticas de inclusão e de exclusão do feminismo" (ALVAREZ et al., 2003, p. 547). Já nos preparativos para a realização da emblemática IV Conferência Mundial sobre a Mulher, realizada em Pequim (1995), relatada muitas vezes como um processo,

\footnotetext{
10 Em ensaio de 2014, Alvarez (p. 16) propõe que o feminismo seja enquadrado como um "campo discursivo de ação", sofisticando sua análise acerca da constituição do campo feminista na América Latina e não o encerrando no conceito de sociedade civil.

${ }^{11}$ Neste Encontro, um dos temas tratados foi "as dimensões escondidas e discriminantes do feminismo: as mulheres indígenas, as mulheres negras, as lésbicas, as pobres [...] em nós", havendo a organização da oficina "El lado oscuro y discriminado del feminismo en el ser y hacer feminista" (ALVAREZ et al., 2003, p. 557; SCHILD, 2017).
} 
existiram relatos críticos sobre o favorecimento de ONGs mais profissionalizadas em detrimento das organizações de base (ALVAREZ et al., 2003; Marta FERNÁNDEZ, 2017). Além disso, houve críticas às próprias políicas de gênero (muitas vezes associadas à agenda do desenvolvimento) estimuladas pelos organismos internacionais, tanto pela sua inserção no contexto neoliberal - e neocolonial para algumas -, quanto pela sua despolitização e seletividade de temas (FERNÁNDEZ, 2017). Vale observar que, de maneira geral, o processo como um todo trouxe aprendizados e experiências importantes, tendo sido apoiado pela grande maioria dos grupos de feministas latino-americanas (Virginia VARGAS, 1996; ALVAREZ et al., 2003). Ele impactou, assim, de diferentes formas, a própria história do feminismo na região.

A questão da inclusão e exclusão no interior desses encontros foi objeto do segundo grande debate dos feminismos latino-americanos, relacionando-se à sua democratização interna. Esta democratização dizia respeito não somente à ampliação da participação de mulheres e feministas em geral e de seus formatos organizativos, mas também à própria representação de identidades, sobretudo, daquelas constituídas como subalternas e subalternizadas, fora e dentro do feminismo. É neste contexto que a noção de um feminismo hegemônico ganharia sentido dentro do próprio feminismo latino-americano - algo como um feminismo hegemonico del Sur (MINÕSO et al., 2014) -, sendo ele em si um feminismo subalterno. Este aspecto é particularmente importante para entender as diferentes relações de subalternidade que informam os feminismos latino-americanos, inclusive, em suas dimensões e espaços internos.

Esta leitura auxilia na problematização do feminismo de(s)colonial como potencialmente articulador dos feminismos subalternos da região, cujo histórico está associado às lutas de mulheres não representadas pelo feminismo que consideram hegemônico - acadêmico, institucional, internacional, (neo)liberal, branco, de classe média. A caracterização de diferenças múltiplas e derivadas da diferença maior "mulher" obedece à dinâmica do descentramento infinito, cujos limites já não podem ser dados pela sujeita principal. E, é justamente desse pluralismo que o particularismo, o exclusivismo ou o antagonismo interno podem surgir, gerando aquilo que anteriormente denominei como paradoxo da representação feminista. Em outras palavras, há uma abertura para discursos capazes de negar o próprio feminismo (antifeminismo?), ${ }^{12}$ compreendido como um movimento ocidental, etnocêntrico e colonizador. Especialmente em relação ao feminismo de(s)colonial, isso é possível devido à construção da diferença colonial (MIGNOLO, 2003) como aquela que articula e atravessa as outras diferenças.

É importante observar que, na América Latina, a preocupação interna do feminismo com a questão das diferenças (classe, raça, etnia, sexualidade) começou a ser provocada pela própria expansão do campo em direção aos diferentes movimentos de mulheres (não necessariamente feministas) já nos anos 1980. Como resposta às dificuldades do contexto marcado pelo empobrecimento e violência, o crescente engajamento e a mobilização feminina diversificaram o perfil também do feminismo: "em contraste à face branca/mestiça e de classe média do feminismo nos seus primeiros tempos, o movimento de mulheres dos anos 1980 floresceu com uma composição predominante de mulheres pobres, trabalhadoras, e/ou negras e indígenas"13 (ALVAREZ et al., 2003, p. 548). A participação de centenas dessas mulheres oriundas dos movimientos de mujeres da América Central foi observada especialmente a partir do Encontro de 1987 ocorrido em Taxco (México). O feminismo latino-americano era apresentado às suas "outras" como consequência de sua própria estratégia de ampliação e organização de mulheres das classes populares.

Devido aos altos níveis de desigualdade em geral e da econômica em particular, a literatura observa que o feminismo latino-americano em sua grande expressão popular nunca pôde prescindir das reivindicações materiais e associadas à classe. Shild (2017), procurando problematizar a aplicabilidade de algumas contribuições de Nancy Fraser para $\circ$ feminismo latino-americano, argumenta: "para las feministas 'populares', así como para muchas mujeres indígenas y de ascendencia africana, las exigencias de justicia de género derivan de la propia situación material. Sus luchas nunca han perdido de vista la crítica de la economía política" (p. 48). A citação remete à conclusão da autora de que reconhecimento cultural e redistribuição

\footnotetext{
12 É claro que podemos compreender e interpretar este fenômeno de diferentes maneiras. Alvarez (2014, p. 7) oferece a seguinte interpretação sobre as tensões do campo feminista: "o poder, os conflitos, as lutas interpretativas, as disputas político-culturais também são elementos constitutivos do campo feminista. Como é o caso em todas as formações políticas, os campos discursivos de ação movimentistas estão sempre minados por desigualdades e relações desiguais de poder. Essas inequidades podem eventualmente ser alteradas, já que o campo feminista está permanentemente em fluxo. Isto é, os campos erguem-se, se estabilizam, reconfiguram-se, reconstroem-se, e periodicamente, se desconstroem e/ou desembocam em ou geram novos e distintos campos. Os fluxos do campo feminista resultam das suas interações dinâmicas com os campos de poder nos quais ele se insere em uma determinada conjuntura histórica. E tais contextos mais amplos, por sua vez, permitem, facilitam, ou até incentivam certas expressões, discursos, e práticas feministas, ao mesmo tempo em que sempre limitam, disciplinam, circunscrevem, reprimem ou até criminalizam outras".

13 Interessante observar que o feminismo indígena passou a ganhar maior visibilidade interna justamente pelas dinâmicas de internacionalização/transnacionalização/globalização (ALVAREZ et al., 2003).
} 
econômica são demandas por justiça historicamente imbricadas para grande parte das lutadoras sociais latino-americanas.

Submersas em várias camadas de subalternidade, o pertencimento geopolítico, geocultural ou geográfico está presente em muitas referências dos feminismos subalternos latino-americanos. De fato, trata-se de uma conformação feminista constantemente situada, uma vez que é possível perceber construções de referências compartilhadas em termos espaciais e culturais positivados: Frontera, Nuestramérica, Abya Yala, Sur. Compreendo que este referencial, permanentemente modificado por novas criações e recriações discursivas, cumpre a importante função de forjar sentidos comuns para o enfrentamento da vivência de condições estruturais semelhantes, desfavoráveis e por vezes brutais - desigualdade, injustiça, violência, pobreza, desemprego. ${ }^{14}$ Pensar, portanto, em macroprocessos e como eles afetam a vida das mulheres comuns constitui-se em uma característica não raro observada nos feminismos latino-americanos como um todo.

Esse raciocínio pode fornecer um entendimento válido sobre as leituras feministas críticas e radicais de processos históricos mais amplos, incluindo as clássicas problematizações sobre capitalismo e patriarcado. Assim, se anteriormente era possível encontrar um discurso antiimperialista herdado das organizações da esquerda revolucionária do passado, o discurso antineoliberal foi sendo estruturado para diferentes feminismos críticos nos últimos trinta anos.

No âmbito dos Encontros, a percepção de que a globalização neoliberal intensificou a pobreza e o trabalho das mulheres marginalizadas devido aos seus impactos no plano local tornou-se mais evidente no final dos anos 1990. Com efeito, da criação do Movimento Zapatista à suspensão da Área de Livre Comércio das Américas (ALCA), a resistência ao neoliberalismo na América Latina forjou um campo social potencialmente contestatório e posteriormente fértil para o movimento altermundialista dos "outros" mundos e globalizações possíveis. Em 2001, a primeira edição do Fórum Social Mundial em Porto Alegre refletiu esse cenário de grandes transformações. Naquele contexto, a noção terceiro-mundista de descolonização não era ecoada, tampouco a globalização neoliberal era reduzida a uma forma de colonialismo - pelo menos para grande parte da esquerda democrática. Contudo, convém reforçar que a crítica ao neoliberalismo está presente desde os anos 1990 no campo discursivo de ação do feminismo latino-americano.

\section{Descolonizacão como utopia política contemporânea: a virada de(s)colonial dos feminismos latino-americanos subalternos}

Precisar o momento da reabilitação do colonialismo como um problema global, regional e nacional é uma tarefa inglória e provavelmente infrutífera. Como e por que a palavra "colonialismo" ressurgiu no século XXI em diferentes circuitos - acadêmicos, teóricos, ativistas - com tanta força? Pergunta semelhante fez Deivison Faustino (2015) em sua importante tese "Por que Fanon? Por que agora?: Frantz Fanon e os fanonismos no Brasil". Em várias partes do mundo e mais tardiamente no Brasil, o interesse pelas teorias críticas ao colonialismo tem crescido nos últimos anos, tanto em espaços acadêmicos e universitários, como também em coletivos políticos e culturais.

O despertar dessa curiosidade aumenta quando se observa que a ideia de descolonização vem sendo reconstruída como um projeto atravessador de dimensões distintas (poder, saber, ser) e variadas (Estado, conhecimento, educação, história, corpo, mente, entre outras), sendo a América Latina seu principal lócus de enunciação teórica. No âmbito empírico, o continente apresentou exemplos inspiradores que alcançaram estruturas constitucionais e instituições estatais, especialmente a partir da originalidade e radicalidade da experiência andina. Em outras partes do mundo, demandas por reestruturação de currículos universitários ou de planos museológicos com base na descolonização podem ser vistas na Inglaterra, Espanha, Bélgica, Estados Unidos, entre outros. Pessoalmente, a compreensão de quais foram as condições que permitiram a politização contemporânea da questão colonial e a reconstrução da descolonização como utopia se colocou como um grande desafio intelectual. Independentemente da afinidade política que se tenha com o tema, entendo que ele seja indicativo de um fenômeno social, político e cultural relevante de ser explicado e interpretado pelo tempo presente. Recentemente, a destruição e a remoção de estátuas relacionadas à memória do colonialismo e da escravidão foram vistas em diferentes países do Atlântico Norte.

O tratamento da questão (anti)colonial não é novo na América Latina, existindo desde a formação do seu pensamento político no século XIX à consolidação de suas Ciências Sociais ao longo do século XX. Também, a ideia esteve no imaginário de diferentes movimentos políticos e sociais. No âmbito deste artigo, tal questionamento mais amplo atinge o feminismo latino-americano, desde os anos 1970 atento e resistente às formas de colonialidade, ainda que não necessariamente com este nome (Ochy CURIEL, 2007). Em termos teóricos, o autodenominado feminismo de(s)colonial

\footnotetext{
${ }^{14}$ Em um continente desigual, violento e machista como a América Latina, são inúmeras as situações de vulnerabilidade pelas quais passa grande parte de sua população feminina. Assim, as demandas por teorias mais "situadas", oriundas de experiências e contextos nos quais sobreviver é resistir, devem ser lidas mais como uma exigência do real do que um diletantismo teórico.
} 
utiliza referências autorais explícitas relacionadas ao giro decolonial, incorporando as contribuições feministas e relacionadas ao gênero que dialogam com esta perspectiva.

O giro decolonial é uma expressão utilizada para designar uma pretensão de virada epistemológica fundamentada nas elaborações teóricas do programa de investigação Modernidade/Colonialidade (M/C). Mobilizando um conjunto variado de influências críticas ao eurocentrismo, à modernidade e à colonialidade, sua proposta é inserir a América Latina no debate global do pós-colonialismo, destacando pontos de continuidade e de ruptura com esta corrente. Apesar de as origens da formação histórica do grupo remontarem ao início dos anos 1990, é no contexto políico do "Left Turns" na América Latina que seus encontros foram desenvolvidos e suas teorizações foram difundidas. ${ }^{15} \mathrm{~A}$ categoria decolonialidade é responsável por reintroduzir e atualizar a noção própria de descolonização, tendo esta última uma presença variada na trajetória do próprio pós-colonialismo enquanto projeto político ou teórico-normativo.

Diferentemente da primeira geração do pós-colonialismo, cuja ideia de descolonização era informada pelo próprio contexto histórico das lutas anticoloniais pela libertação nacional, o pós-colonialismo da segunda geração não necessariamente se preocupou em elaborar um projeto descolonizador. É dessa versão pós-estruturalista, mais popularizada e conhecida do póscolonialismo, que o giro decolonial - entendido aqui como terceira geração do pós-colonialismo ou inflexão latino-americana do pós-colonialismo - pretende se diferenciar (BALLESTRIN, 2013; $2017 b)$. É importante observar que cada vez mais suas ideias são difundidas para além da América Latina, e assim como no próprio pós-colonialismo, o revisionismo histórico está na base de suas intervenções.

Novamente, será difícil apontar com exatidão o início dos encontros teóricos entre o feminismo latino-americano e o giro decolonial, apesar de María Lugones (2008; 2014) ser a autora quem primeiro faz a defesa normativa da ideia. No sentido inverso, o ponto de contato mais evidente remete à autocrítica do $\mathrm{M} / \mathrm{C}$ em relação à ausência da discussão de gênero no seu projeto teórico coletivo. Ela está documentada no artigo do antropólogo Arturo Escobar (2003), importante expoente do grupo a estimular esse debate. Definindo-se desde jovem como feminista (ESCOBAR, 2014, p. 12), é ele quem oportuniza o colóquio Tejiendo de otro modo: feminismo, epistemología y apuestas descoloniales en Abya Yala ocorrido em Chapel Hill em abril de 2012, escrevendo posteriormente o Prefácio do livro homônimo resultado desse encontro. A relevância desse livro para o debate pode ser lida nas palavras do próprio Escobar (2014):

me atrevo a afirmar que la reflexión propiciada por este volumen, en la intersección de feminismos y pensamiento decolonial, es una de las propuestas más importantes y de avanzada en los debates teórico-políiticos en el continente. Por un lado, enriquece al pensamiento decolonial con sus reflexiones críticas sobre el género, comenzando por la pregunta sobre la pertinencia de la categoría misma de género para analizar las dinámicas que queremos entender. Por otro lado, infunde una conciencia más aguda en los diversos feminismos sobre las múltiples facetas de la colonialidad, incluyendo cómo estos pudieran albergar en su seno formas moderno/ coloniales de poder, ser y conocer (p. 12).

A coletânea organizada por Yuderkys Espinosa Miñoso, Diana Gómez Correal e Karina Ochoa Muñoz (2014) oferece um material esclarecedor sobre as propostas e leituras de(s)coloniais para o feminismo. De acordo com Céli Regina Pinto (2010), o feminismo

\begin{abstract}
é um movimento que produz sua própria reflexão crítica, sua própria teoria. Esta coincidência entre militância e teoria é rara e deriva-se, entre outras razóes, do tipo social de militante que impulsionou, pelo menos em um primeiro momento, o feminismo da segunda metade do século XX: mulheres de classe média, educadas, principalmente, nas áreas das Humanidades, da Crítica Literária e da Psicanálise (p. 15).
\end{abstract}

Esta citação interessa para entender o feminismo de(s)colonial em dois aspectos. Primeiro, porque ele é um movimento que produz suas próprias reflexões e teorias, defendendo abertamente a congruência entre prática e teoria; segundo, porque suas militantes, mulheres produtoras de ação e conhecimento, possuem um perfil social bem diferente do acima destacado. É muito interessante entrar em contato com textos que ora podem ser lidos como discurso político, ora como documento histórico, ora como proposição teórica. Esta mistura explícita e intencional das ordens analíticas, políticas e normativas fascina pelo desafio de compreender o texto em seu contexto de luta política real - não encerrado ou limitado pelas exigências acadêmicas ou fronteiras disciplinares. Justamente por isso, deve-se estar atenta para avançar na extração e seleção dos aspectos que se pretende compreender e interpretar.

\footnotetext{
${ }^{15}$ Isto é, no contexto de ampliação democrática com maior participação do Estado na elaboração de políiticas públicas e diminuição de desigualdades por parte dos governos eleitos de esquerda e centro-esquerda na região. As expressões Onda/Maré Rosa ou Pós-neoliberalismo também são utilizadas para designar este ciclo político e ideológico no continente, cujo grau de enfrentamento ao neoliberalismo variou de acordo com cada país.
} 
Em outro lugar, analisei as categorias "sistema-mundo moderno/colonial de gênero" e "feminismo descolonial", entendendo-as como as intervenções diretas de Lugones a partir das aberturas e brechas deixadas pelos autores/interlocutores do M/C - A. Quijano, A. Escobar, W. Mignolo, R. Grosfoguel - em relação à questão gênero/sexualidade/feminismo. Também, incorporei às discussões sobre feminismo descolonial e do sul as autoras argentinas K. Bidaseca e R. Segato. No âmbito deste artigo, é importante avançar na relação entre teoria e prática do feminismo de(s)colonial, dada sua contribuição original para os feminismos contemporâneos.

O feminismo de(s)colonial também deve ser compreendido como um movimento emergente, capaz de fazer orbitar em torno da ideia prática e teórica de "descolonização" diferentes movimentos subalternos de mulheres e feministas latino-americanos. A grande maioria destes movimentos já atua há décadas no continente e possui cruzamentos entre si, como, por exemplo, o feminismo indígena e comunitário. De acordo com Curiel (2014),

las primeras experiencias descolonizadoras en el feminismo las encontramos precisamente en feministas racializadas, en las lesbianas, en mujeres del 'Tercer Mundo', aquellas que se resistieron a la dominación patriarcal, racista y heterosexista, desde posiciones subalternizadas (p. 327).

A transformação da ideia de descolonização em um princípio orientador da prática e da teoria é percebida em vários textos preocupados em definir o significado de "descolonizar" de um ponto de vista feminista ou de gênero. Novamente, existem diferentes posições, ainda que o esforço recente seja visivelmente mais construtivo e colaborativo do que o contrário: "el feminismo descolonial no es un campo uniforme. Pensarlo de manera homogénea le haría perder gran parte de su riqueza" (MIÑOSO et al., 2014, p. 36).

A descolonização do feminismo, do conhecimento (inclusive da teoria feminista), do gênero e do Estado são quatro eixos importantes de intervenção do feminismo de(s)colonial. É importante observar que os discursos sobre cada um destes aspectos variam de acordo com as próprias posições das autoras dentro do campo feminista latino-americano e de suas regiões de atuação. Assim, há discursos que reivindicam autonomia, rebeldia, transgressão e desobediência; outros, ainda, procuraram participar no projeto de refundação do Estado boliviano, entendendo que "não há descolonização sem despatriarcalização" (Patrícia CHÁVEZ et al., 201 1). A região andina foi, sem dúvida, palco fundamental para as discussões envolvendo muitos dos temas abordados pelos feminismos descoloniais, descolonizadores ou descolonizantes, principalmente na Bolívia e no Equador (Soledad VAREA; Sofía SARAGOCIN, 2017). A discussão sobre Bien Vivir, o papel da comunidade e o princípio da complementariedade dos gêneros foi teorizada por Julieta Paredes (2014), desconstruindo fortemente a ideia de equidade de gêneros e desvelando o "entronque patriarcal entre el patriarcado precolonial y el occidental" (p. 71).

A produção teórica "desde a diferença colonial" ganha vários sentidos para as autoras e interlocutoras feministas de(s)coloniais (MIÑOSO et al. , 2014, p. 19), inclusive em relação ao próprio feminismo. O feminismo de(s)colonial, ao rearticular e reabilitar a utopia da descolonização como seu núcleo distintivo, difunde narrativas e problematizações que desafiam o próprio feminismo como lugar de emancipação das mulheres. O caráter ocidental, colonial e neoliberal do feminismo é bastante ressaltado em alguns textos mais críticos, havendo menção constante ao feminismo hegemônico do Sul e poucas sinalizações de diálogo. Se bem que, em termos de influências teóricas, os feminismos materialista francês, pós-colonial e pós-estruturalista são reconhecidos como importantes para algumas discussões conceituais (MIÑOSO et al., 2014). Por vezes, a recusa de construção junto com os feminismos hegemônicos do Sul é explícita, pois se entende que a lógica da colonialidade pode ser aplicada ao próprio feminismo latino-americano, dadas suas origens, projeção transnacional e utilizações teóricas principais. Citando Ochy Curiel e Breny Mendoza, Miñoso (2014) entende que "hay un origen mayoritariamente burgués, blanco/mestizo, urbano, y heteronormativo del feminismo latinoamericano" (p. 314).

Trata-se, assim, de abandonar a representação das "outras do feminismo" para construir "feminismos outros" representantes do descentramento da "mulher latino-americana". Para Curiel (2014),

descolonizar para las feministas latinoamericanas y caribeñas supondrá superar el binarismo entre teoría y práctica, [pues le potenciaría] para [poder] generar teorizaciones distintas, particulares que mucho pueden aportar para realmente descentrar el sujeto euronorcéntrico y la subalternidad que el mismo feminismo latinoamericano reproduce en su interior. De no ocurrir esto, seguiremos analizando nuestras experiencias con los ojos imperiales, con la conciencia planetaria europea y [norteamericana] que definen al resto del mundo como lo Otro incivilizado y natural, irracional y no verdadero (p. 333).

Em suma, descolonizar o feminismo implica descolonizar também sua produção teórica, ou seja, considerar as experiências, as vozes e as elaborações das mulheres subalternizadas. Esta intenção dialoga com as epistemologias e teorias do sul, no que diz respeito à valorização do conhecimento (geopoliticamente) situado das mulheres latino-americanas, partindo "de un trabajo de revisión crítica del papel y la importancia que han tenido las mujeres en la realización y 
resistencia de sus propias comunidades" (MIÑOSO et al., 2014, p. 32). Isso faz com que suas entusiastas afirmem:

Podemos decir, sin temor a equivocarnos, que el feminismo descolonial abre un campo fértil de producción teórica sin igual en el feminismo regional que habrá de dejar sus frutos importantes en una reconceptualización propia de la opresión y una política más adecuada a los intereses de la mayoría de las mujeres y sus comunidades en Abya Yala (MIÑOSO et al., 2014, p. 33).

A referência no plural dos feminismos descoloniais considera então a heterogeneidade de sujeitas na construção, inclusive teórica, deste projeto que radicalmente se opõe aos essencialismos identitários:

Pero, ¿de qué hablamos cuando hablamos de feminismo descolonial? El feminismo descolonial es un movimiento en pleno crecimiento y maduración que se proclama revisionista de la teoría y la propuesta política del feminismo desde lo que considera su sesgo occidental, blanco y burgués. Entendemos que el feminismo descolonial aglutina las producciones de pensadoras, intelectuales, activistas feministas, lesbianas feministas, afrodescendientes, indígenas, mestizas pobres, así como algunas académicas blancas comprometidas con la tarea de recuperación histórica de un nombre propio, de una teoría y práctica feminista antirracista en Abya Yala (MIÑOSO et al., 2014, p. 32).

Por fim, é importante marcar a diferença entre "feminismos descoloniais" (no plural e com "s") do feminismo decolonial (no singular e sem "s"). Ainda que ambas as expressões possam ser utilizadas de maneira intercambiável, a segunda acaba por estar mais diretamente associada ao projeto teórico decolonial do grupo M/C. Por ocasião da Introdução de uma publicação da Red de Feminismos Descoloniais, Márgara Millán (2014) assim esclarece:

Decidimos optar por el uso de la palabra descolonial y no decolonial para distinguirnos de la teoría de la decolonialidad. A pesar de que varias de las autoras retoman conceptosclave de la reflexión decolonial, lo que nos caracteriza es un permanente ejercicio de apertura frente a hechos que nos llaman a la reflexión, a partir de los cuales es posible desplegar y desagregar un pluriverso temático, encontrando en este sitio nuestros propios gestos descolonizantes. Entendemos entonces que lo descolonial es más un proceso vivo que una teoría cerrada o una escuela de pensamiento (p. 11).

Por esta razão, optei pela utilização feminismo de(s)colonial ao longo do presente texto, de modo a cotejar ambas as perspectivas, considerar a própria tradução da língua inglesa para a portuguesa e espanhola e marcar a orientação teórico-analítica do presente texto.

\section{Considerações finais}

Neste artigo procurei entender o feminismo de(s)colonial como um feminismo subalterno em sua pretensão de articulação de diferentes feminismos latino-americanos (também subalternos): indígena, comunitário, lésbico, negro, entre outros. Por meio da produção textual de mulheres interlocutoras e apoiadoras do feminismo de(s)colonial, observa-se a mistura das ordens analíticas, políticas e normativas, indicando um universo complexo de produção interativa entre ação e conhecimento, prática e teoria. As proposições teóricas e conceituais no contexto de luta real adquirem um valor muito significativo, pois existem intencionalidade explícita e capacidade teórica notável das muitas autoras e interlocutoras do feminismo de(s)colonial - várias delas feministas acadêmicas, pesquisadoras, educadoras e ativistas. As condições dessa produção interativa têm muito a dizer sobre a geopolítica do conhecimento que também atravessa a lógica da teoria feminista; daí a reivindicação da descolonização das próprias teorias políticas e feministas utilizadas pelos feminismos latino-americanos.

Também, sugeri que o feminismo de(s)colonial exemplifica aquilo que chamei de paradoxo da representação feminista. Podem ou devem existir limites para o pluralismo dentro do feminismo? Pensar nesta questão, atualmente, é uma das tarefas mais delicadas do movimento feminista. A importância deste debate é ainda atual e estratégica: tanto pelo crescimento do movimento feminista em toda sua democraticidade, quanto pela contraofensiva reacionária contra ele uma "guerra" contra a "ideologia de gênero" como inimiga a ser eliminada. Nesta reação de proporções globais, existe uma clara tentativa de reduzir o feminismo em suas múltiplas expressões e versões, tornando-o responsável pela decadência de certos valores que a contraofensiva neoconservadora procura resgatar. Ainda que a condenação do movimento feminista não seja propriamente novidade, é preciso reconsiderar, mediante o antifeminismo crescente - inclusive de mulheres - estratégias feministas atentas ao novo contexto global e regional no qual se desenvolvem as lutas políticas. Parece-me cada vez mais necessário fortalecer e legitimar o feminismo como movimento social protagonista na infindável luta histórica pela cidadania. Isso não implica desconsiderar o fato de que grandes movimentos revolucionários na história foram capazes de produzir contradições capazes de questionar sua própria causa original. 
Obviamente, o problema não está no alargamento de suas diferentes organizações e representações. Pelo contrário, ele é responsável pela sua popularização, ampliação e adesão das novas gerações. Assim, defender algum tipo de limite para a projeção das (sub)identidades feministas não condiz com os objetivos do próprio movimento, sendo negativa a resposta à pergunta acima. Mas e quando este alargamento transforma as mulheres e seus movimentos em antagonistas no interior do próprio movimento feminista? E quando este alargamento permite suspender a validade e a desejabilidade do próprio feminismo, condenado a uma categoria colonial e ocidental promotora de desigualdades e colonialidades de mulheres sobre mulheres? Como lutar pela constante democratização interna do movimento feminismo sem reforçar a lógica do antagonismo capaz de gerar, inclusive, um antifeminismo? Semelhantes questionamentos podem ser aplicados à própria teoria democrática.

A globalização e o global não podem ser reduzidos ao colonialismo e ao colonial, pela complexidade das interações, racionalidades e processos que têm sido estabelecidas nas relações transnacionais entre diferentes atores e instituições - locais, nacionais, regionais, internacionais. Da mesma forma, o feminismo, embora seja capaz de produzir relações de poder e desigualdades internas como todo o movimento social, não pode ser simplificado, rebaixado ou igualado ao colonialismo - um processo histórico violento de subjugação, eliminação e classificação de povos inteiros através dos séculos. Isso possui validade não somente heurística, como também política e estratégica.

Em um contexto de ascensão de discursos antifeministas e publicamente misóginos - e também antiglobalistas, anticientíficos e anti-humanistas -, o movimento feminista talvez precise repensar suas estratégias (internas e externas) para o enfrentamento de um cenário crescentemente autoritário, no qual ele se tornou um alvo de ataque sem precedentes. Isso não significa abdicar e rejeitar lutas por representação e representatividade, mas contextualizá-las nas exigências do momento histórico atual, ainda que possam haver muitas variações e relativizações. Quando o feminismo de(s)colonial tomou forma, o horizonte em relação à democracia era absolutamente diferente, tanto na América Latina quanto no mundo. Apesar da formação histórica colonial e violenta do Estado nacional, assim como da persistência das desigualdades estruturais, o regime político democrático fundamenta e importa para as lutas por justiça social e ambiental no continente. A contrarrevolução neoliberal e neoconservadora a que se assiste é também fruto desse diagnóstico, sendo o atual momento latinoamericano dramático para alguns países que ousaram imprimir rumos diferentes ou alternativos ao histórico dominante da região, incluindo o trágico desfecho do projeto estatal descolonizador e despatriarcalizador na Bolívia. É fundamental a incorporação do problema da democracia e de sua retomada em vários países do continente pelo projeto decolonial, diante do retorno do autoritarismo e do fascismo em várias partes do mundo.

\section{Referências}

ALVAREZ, Sonia E. "Feminismos Latino-Americanos". Revista Estudos Feministas, v. 6, n. 2, 1998.

ALVAREZ, Sonia E. "Para além da sociedade civil: reflexões sobre o campo feminista". Cadernos Pagu, n. 43, p. 13-56, 2014.

ALVAREZ, Sonia E; FRIEDMAN, Elisabeth J.; BECKMAN, Ericka; BLACKWELL, Maylei; CHINCHILLA, Norma Stoltz; LEBON, Nathalie; NAVARRO, Marysa; TOBAR, Marcela Ríos. "Encontrando os feminismos latinoamericanos e carinbenhos". Revista Estudos Feministas, v. 11, n. 2, 2003.

BALLESTRIN, Luciana. "América Latina e o giro decolonial". Revista Brasileira de Ciência Política, n. 11 , p. 89-117, 2013.

BALLESTRIN, Luciana. "Feminismos Subalternos". Revista Estudos Feministas, v. 25, n. 3, p. 10351054, 2017a.

BALLESTRIN, Luciana. "Modernidade/Colonialidade sem "Imperialidade"? O Elo Perdido do Giro Decolonial". Dados Revista de Ciências Sociais, v. 60, n. 2, p. 505-540, 201 7b.

BIROLI, Flávia. "Violence against Women and Reactions to Gender Equality in Politics". Politics \& Gender, v. 14, n. 4, p. 681-685, 2018.

CHÁVEZ, Patrícia; QUIROZ, Tania; MOKRANIS, Dunia; LUGONES, María. Despatriarcalizar para descolonizar la gestión pública. Cuadernos para el debate y la descolonización. Bolivia: Vicepresidencia del Estado Plurinacional de Bolivia, 2011.

CURIEL, Ochy. "Crítica poscolonial desde las prácticas políticas del feminista antirracista". Nómadas, n. 27, p. 92-101, 2007. 
CURIEL, Ochy. "Hacia la construcción de un feminismo descolonizado". In: MIÑOSO, Yuderkys Espinosa; CORREAL, Diana Gómez; MUÑOZ, Karina Ochoa (Eds.). Tejiendo de otro modo: Feminismo, epistemología y apuestas descoloniales en Abya Yala. Popayán: Universidad del Cauca, 2014.

ESCOBAR, Arthuro. "Mundos y conocimientos de otro modo: el programa de investigación modernidad/colonialidad latinoamericano". Tabula Rasa, n. 1, p. 58-86, 2003.

ESCOBAR, Arturo. "Prefácio”. In: MIÑOSO, Yuderkys Espinosa; CORREAL, Diana Gómez; MUÑOZ, Karina Ochoa (Eds.). Tejiendo de otro modo: Feminismo, epistemología y apuestas descoloniales en Abya Yala. Popayán: Universidad del Cauca, 2014.

FAUSTINO, Deivison. Por que Fanon, por que agora? Frantz Fanon e os fanonismos no Brasil. 2015. 260p. Tese (Doutorado) - Programa de Pós-Graduação em Sociologia, Universidade Federal de São Carlos, São Carlos.

FEDERICI, Silvia. Calibã e a Bruxa. São Paulo: Elefante, 2017.

FERNÁNDEZ, Marta C. "Políticas de Género, Colonialidad y Neoliberalismo: Una Mirada Crítica al 'Proceso a Beijing' en Bolivia". In: VAREA, Soledad; ZARAGOCIN, Sofía (Comps.). Feminismo y Buen Vivir: utopías decoloniales. Cuenca: Pydlos, 2017.

LUGONES, María. "Colonialidad y género". Tabula Rasa, n. 9, p. 73-101, 2008.

LUGONES, María. "Rumo a um feminismo descolonial". Revista Estudos Feministas, v. 22, n. 3, p. 935952, 2014.

MIGNOLO, Walter. Histórias locais, projetos globais: colonialidade, saberes subalternos e pensamento liminar. Belo Horizonte: EDUFMG, 2003.

MILLÁN, Márgara (Coord.). Mas allá del feminismo: caminos para andar. México: Red de Femismos Descoloniais, 2014.

MIÑOSO, Yuderkys Espinosa; CORREAL, Diana Gómez; MUÑOZ, Karina Ochoa. "Introducción”. In: MIÑOSO, Yuderkys Espinosa; CORREAL, Diana Gómez; MUÑOZ, Karina Ochoa (Eds.). Tejiendo de otro modo: Feminismo, epistemología y apuestas descoloniales en Abya Yala. Popayán: Universidad del Cauca, 2014.

MIÑOSO, Yuderkys Espinosa. "Ełnocentrismo y colonialidad en los feminismos latino-americanos: complicidades y consolidación de las hegemonías feministas en el espacio transnacional". In: MIÑOSO, Yuderkys Espinosa; CORREAL, Diana Gómez; MUÑOZ, Karina Ochoa (Eds.). Tejiendo de otro modo: Feminismo, epistemología y apuestas descoloniales en Abya Yala. Popayán: Universidad del Cauca, 2014.

MORTON, Stephen. Gayatri Chakravorty Spivak. London \& New York: Routledge, 2004. (Routledge Critical Thinkers)

PAREDES, Julieta. Hilando fino desde el Feminismo Comunitário. México, 2014. (Comunidad Mujeres Creando Comunidad)

PINTO, Céli Regina Jardim. "Feminismo, história e poder". Revista de Sociologia e Política, Curitiba, v. 18, n. 36, p. 15-23, jun. 2010.

PORTO-GONÇALVES, Carlos Walter. "Verbete 'Abya Yala'". Portal da Enciclopédia Latino-Americana, 2006. Disponível em http://latinoamericana.wiki.br/verbetes/a/abya-yala. Acesso em 31/01/2020.

SCHILD, Verónica. "Feminismo y neoliberalismo en América Latina". Nueva Sociedad, n. 65, 2017. Disponível em https://nuso.org/articulo/feminismo-e-neoliberalismo-na-america-latina/. Acesso em 08/05/2018.

VAREA, Soledad; ZARAGOCIN, Sofía (Comps.). Feminismo y Buen Vivir: utopías decoloniales. Cuenca: Pydlos, 2017.

VARGAS, Virginia V. "Disputando el espacio global: el movimiento de mujeres y la IV Conferencia Mundial de Beijing". Nueva Sociedad, n. 141, p. 43-53, 1996.

Luciana Ballestrin (luciana.ballestrin@ufpel.edu.br) é Professora Associada de Ciência Política no Programa de Pós-Graduação de Ciência Política e no curso de Relações Internacionais 
da Universidade Federal de Pelotas. É editora da Revista Sul-americana de Ciência Política e coordenadora do grupo de pesquisa Teoria Política Global.

\section{COMO CITAR ESSE ARTIGO DE ACORDO COM AS NORMAS DA REVISTA}

BALLESTRIN, Luciana. "Feminismo De(s)colonial como Feminismo Subalterno Latino-Americano". Revista Estudos Feministas, Florianópolis, v. 28, n. 3, e75304, 2020.

\section{CONTRIBUIÇÃO DE AUTORIA}

Não se aplica.

\section{FINANCIAMENTO}

Não se aplica.

\section{CONSENTIMENTO DE USO DE IMAGEM}

Não se aplica.

APROVAÇÃO DE COMITÊ DE ÉTICA EM PESQUISA

Não se aplica.

\section{CONFLITO DE INTERESSES}

Não se aplica.

\section{LICENÇA DE USO}

Este artigo está licenciado sob a Licença Creative Commons CC-BY International. Com essa licença você pode compartilhar, adaptar, criar para qualquer fim, desde que atribua a autoria da obra.

HISTÓRICO

Recebido em 30/06/2020

Aprovado em 08/07/2020 